\title{
Obesity and Preoperative Anaemia as Independent Risk Factors for Sternal Wound Infection After Coronary Artery Bypass Graft Surgery with Pedicled (Non-Skeletonized) Internal Mammary Arteries: The Role of Thoracic Wall Ischemia?
}

This article was published in the following Dove Press journal: Vascular Health and Risk Management

\author{
Aurélie Brunet ${ }^{\prime}$ \\ Yohan N'Guyen ${ }^{1, *}$ \\ Annick Lefebvre ${ }^{2, *}$ \\ Anne Poncet ${ }^{3}$ \\ Ailsa Robbins' \\ Odile Bajolet $^{2}$ \\ Yves Saade ${ }^{3}$ \\ Vito Giovanni Ruggieri ${ }^{3} *$ \\ Sylvain Rubin ${ }^{3, *}$

\begin{abstract}
'Internal Medicine, Infectious Diseases University Hospital, Reims, France; ${ }^{2}$ Operational Hygiene Team, Robert Debré University Hospital, Reims, France; ${ }^{3}$ Thoracic and Cardiovascular Surgery, Robert Debré University Hospital, Reims, France

*These authors contributed equally to this work
\end{abstract} \\ and Clinical Immunology, Robert Debré
}

Purpose: Obesity remains statistically associated with coronary artery disease, for which coronary artery bypass graft surgery $(\mathrm{CABG})$ remains the standard of care. However, obesity is also associated with sternal wound infection (SWI) which is a severe complication of CABG despite advances in surgery and in infection prevention and control. Strategies to reduce the incidence of SWI are still being investigated, and we therefore conducted a retrospective study to revisit factors other than obesity associated with SWI after CABG.

Patients and Methods: Data were extracted from the medical records of 182 patients who underwent elective on-pump CABG using one or both pedicled internal mammary artery grafts in Reims University Hospital between May 2015 and May 2016. All preoperative or perioperative variables with a $p$ value $<0.10$ in univariate analysis were entered into a stepwise logistic regression model.

Results: Among the 182 patients (145 male (79.6\%), median age 68.0 [45.0-87.0] years), 138 (75.8\%) underwent CABG using bilateral internal mammary artery grafts. Median BMI was 27.7 [18.7-50.5] kg/m² and there were $51(28.0 \%)$ and $79(43.4 \%)$ patients with obesity and overweight, respectively. Twenty-three out of the 182 patients $(12.6 \%)$ developed SWI. In-hospital mortality was not statistically different between patients with and without SWI but the median length of stay was $(6.0$ [2.0-38.0] versus 5.0[3.0-21.0] days in the intensive care unit, $\mathrm{p}=0.03$, and 26.0 [9.0 $134.0]$ versus 9.0 [7.0-51.0] days in hospital, $\mathrm{p}<0.0001)$. Obesity and preoperative anaemia were independently associated with SWI, as was the number of red blood cell (RBC) units transfused (OR 14.61 [2.64-80.75], OR 4.64 [1.61-13.34] and OR 1.27 [1.02-1.58], respectively).

Conclusion: The independent association of SWI with the number of RBC units transfused and the existence of preoperative anaemia and obesity suggests a mechanism of thoracic wall ischemia in SWI after CABG, thus leaving insufficient perfusion of the thoracic wall in patients with obesity. Medical strategies are warranted to try to prevent this costly complication.

Keywords: obesity, preoperative anaemia, coronary artery bypass graft surgery, internal mammary arteries

\section{Introduction}

Obesity, which is becoming more prevalent in developed countries, remains statistically associated with coronary artery disease (CAD). ${ }^{1}$ The prognosis of CAD after treatment among patients with obesity is good and even better than that observed
Correspondence: Yohan N'Guyen Internal Medicine, Infectious Diseases and Clinical Immunology, Robert Debré University Hospital, Avenue du général Koenig, Reims 51092, France

Tel (+33) 326789422

Fax (+33) 326784090

Email yohan.nguyen@wanadoo.fr
Vascular Health and Risk Management 2020:16 553-559

submit your manuscrip

DovePress $f y$ in $\boldsymbol{t}$ 
among patients without obesity. ${ }^{1}$ For years, standard care for CAD was coronary artery bypass graft surgery (CABG), which is still today (after the development of percutaneous transluminal coronary angioplasty) the standard of care for CAD with complex lesions, especially in the case of triple vessel CAD. ${ }^{2}$

However, over the last 30 years, obesity has also been associated with sternal wound infection (SWI) after CABG. ${ }^{3}$ Over this period, advances in surgery and in infection prevention and control have led to a reduced rate of infections and of the need for further surgery. ${ }^{4-6}$ Saphenous vein graft has been supplanted by more durable internal mammary artery graft, and skeletonised internal mammary artery grafts have been associated with a lower incidence of infection than pedicled grafts. ${ }^{4,5}$ The incidence of postoperative infection has also been reduced by the implementation of systematic Staphylococcus aureus carriage decontamination before $\mathrm{CABG} .{ }^{6}$ Despite all this, SWI is still a severe complication of CABG, with significant morbidity, and strategies to reduce the incidence of SWI are still being investigated. ${ }^{7,8}$ Furthermore, areas of uncertainties persist, such as the benefit of skeletonised internal mammary artery graft in real-life setting, or the impact of bilateral internal mammary artery grafts on the occurrence of SWI among patients with obesity and/or diabetes mellitus. ${ }^{9-13}$

We therefore conducted a retrospective study to revisit factors other than obesity associated with SWI after CABG using standard pedicled internal mammary artery graft before the implementation of systematic Staphylococcus aureus carriage decontamination in our centre.

\section{Patients and Methods Study Design}

Data were extracted from the medical records of all patients who underwent on-pump CABG in Reims University Hospital between May 2015 and May 2016. The patients were not required to provide individual consent because of the retrospective and non-interventional nature of this study, in accordance with French legislation. No patient had previously objected to the further use of their medical data at the time of surgery. Data confidentiality was preserved throughout this internal study (Reims University Hospital GDPR register number RMR00406082020), in accordance with the principles of the Declaration of Helsinki.
During the study period, all patients who underwent elective CABG using one or both pedicled internal mammary artery grafts with or without concomitant valve surgery were included. Patients who underwent 1) aortic dissection surgery, 2) CABG using saphenous vein graft only or using skeletonised internal mammary artery graft, 3) valve replacement surgery without associated $C A B G, 4)$ emergency $\mathrm{CABG}$ or 5) off-pump elective $\mathrm{CABG}$ were excluded.

\section{Definitions}

According to the Centre for Disease Control (CDC) definitions, SWI was defined as the presence of one of the following criteria within 90 days following surgery: 1) fever, chest pain or sternal instability associated with purulent discharge from the mediastinal area, or positive blood culture; 2) evidence of mediastinitis during revision surgery; 3 ) the presence of organism cultured from mediastinal tissue/fluid obtained during revision surgery or after needle aspiration. ${ }^{7}$ However, there is evidence for genuine surgical site infection that does not fulfill this definition. ${ }^{7}$ In order to go beyond the CDC criteria, SWI was defined here as dehiscence of the sternotomy wound, local pain, fever or discharge associated with the presence of organism cultured from mediastinal tissue, or superficial discharge or blood and/or with antibiotic prescription (without any other explanation), irrespective of the need for revision surgery. Deep SWI was defined as the need for sternum bone reopening during revision surgery. Otherwise, SWI was defined as superficial. ${ }^{7}$ Wound infections following saphenous vein or radial artery harvesting were not considered.

Obesity and overweight were defined as a Body Mass Index (BMI) $\geq 30 \mathrm{~kg} / \mathrm{m}^{2}$ and from 25 to $30 \mathrm{~kg} / \mathrm{m}^{2}$, respectively. Preoperative anaemia was defined as a haemoglobin level $<120 \mathrm{~g} / \mathrm{L}$ for women and $<130 \mathrm{~g} / \mathrm{L}$ for men. The delta haemoglobin value was defined as the difference between postoperative and preoperative haemoglobin values.

Immunodeficiency was defined in case of diabetes mellitus, autoimmune disease, corticosteroid or immunosuppressive therapy. Unbalanced diabetes mellitus was defined, according to the French Society of Anaesthesia and Intensive Care Medicine definition, as fasting glycemia $>10 \mathrm{mmol} / \mathrm{L}$ or glycated haemoglobin $\mathrm{HbA} 1 \mathrm{C}>8 \%$ before surgery. Acute renal failure (ARF), ASA, NNIS, SAPS2 and the Charlson index have been defined elsewhere. ${ }^{14-18}$ 


\section{Statistical Analysis}

Quantitative variables expressed as median + range were compared using the Mann Whitney $U$-test and qualitative variables expressed as percentages were compared using Fisher's exact test or Pearson's Chi-square test, as appropriate. A $p$ value $<0.05$ was considered as significant. All preoperative or perioperative variables with a $p$ value $<0.10$ were entered into a stepwise logistic regression model. Statistical analyses were performed using Stat view 5.0 software (SAS institute).

\section{Results Study Population}

One hundred and eighty-two patients (145 males (79.6\%), median age 68.0 [45.0-87.0] years) underwent elective CABG using one or both internal mammary artery grafts over the study period. A history of diabetes mellitus, arterial hypertension and hypercholesterolemia were evidenced in $64(35.1 \%), 133(73.0 \%)$ and 121 (66.4\%) cases, respectively. Among the 64 patients with diabetes mellitus, 19 (29.6\%) were being treated with insulin before surgery. Forty-one patients $(22.5 \%)$ were smokers. Median BMI was $27.7[18.7-50.5] \mathrm{kg} / \mathrm{m}^{2}$ and there were $51(28.0 \%)$ and $79(43.4 \%)$ patients with obesity and overweight, respectively.

\section{Surgical Procedures}

Twenty-six patients (14.3\%) had concomitant valve surgery. Median number of arterial and venous grafts was 2.0 [1.0-4.0]. One hundred and thirty-eight patients (75.8\%) underwent CABG using bilateral internal mammary artery grafts and 50 patients (27.4\%) underwent sequential CABG.

Sixteen out of the 64 diabetic patients $(25.0 \%)$ had unbalanced diabetes mellitus and 5 of the 41 smokers $(12.1 \%)$ did not stop smoking before the surgical procedure.

All patients received 48 hours of prophylactic antibiotic therapy with first- or second-generation cephalosporin, except for 15 patients $(8.2 \%)$ who received vancomycin. A double dose of cephalosporin was given to 8 of the 14 patients $(57.1 \%)$ with $\mathrm{BMI} \geq 35 \mathrm{~kg} / \mathrm{m}^{2}$.

The median preoperative haemoglobin value was 135.0 [95.0-183.0] g/L, and 51 patients $(28.0 \%)$ had preoperative anaemia. No preoperative red blood cell (RBC) transfusion was performed. The median postoperative and delta haemoglobin values were 115.0 [88.0-149.0] $\mathrm{g} / \mathrm{L}$ and
$-20.0[-64.0-+22.0] \mathrm{g} / \mathrm{L}$. A median number of $2.0[0.0-$ 29.0] RBC units were transfused during $C A B G$ or in the Intensive Care Unit (ICU) for 131 of the 182 patients $(71.9 \%)$.

\section{Sternal Wound Infections}

Twenty-three out of the 182 patients (12.6\%) developed SWI (versus none of the 112 excluded patients who only underwent elective valve surgery over the study period). Only 6 of these 23 SWI cases fulfilled the CDC criteria, while 10 cases corresponded to deep SWI.

In-hospital mortality was not statistically different between patients with and without SWI ( 1 out of 23 $(4.3 \%)$ versus 1 out of $159(0.6 \%) ; p=0.23$, according to Fisher's exact test) but the occurrence of ARF was statistically more frequent among patients with SWI than among those without (11 out of $23(47.8 \%)$ versus 32 out of $159(20.1 \%) ; p=0.003)$. Twelve of the 23 patients with SWI $(52.1 \%)$ required revision surgery versus 3 of the 159 patients without SWI $(1.9 \%) ; \mathrm{p}<0.0001$, according to Fisher's exact test.

The median length of stay in ICU and in hospital was statistically longer among patients with SWI than among those without (6.0 [2.0-38.0] versus 5.0[3.0-21.0] days, $\mathrm{p}=0.03$ and 26.0 [9.0-134.0] versus 9.0 [7.0-51.0] days, $\mathrm{p}<0.0001$, respectively). There were no significant differences for extracorporeal circulation or surgery durations (Table 1).

Pre- or perioperative factors significantly associated with SWI and univariate logistic regression results are shown in Table 1 and Supplementary Table 1 respectively. Factors that were considered as a consequence of SWI (inhospital mortality, ARF, need for revision surgery and length of stay in ICU or in hospital) were not entered into the multivariate logistic regression model, the results of which are shown in Table 2. Across all 182 patients, the factors independently associated with SWI were obesity, preoperative anaemia and the number of RBC units transfused (Table 2). Hosmer and Lemeshow goodness-of-fit and the $\mathrm{c}$-statistic yielded $\mathrm{p}=0.89$ and $\mathrm{p}=0.81$, respectively. Logistic regression using the quantitative variables body mass index $\left(\mathrm{kg} / \mathrm{m}^{2}\right)$ and preoperative haemoglobin $(\mathrm{g} / \mathrm{L})$ yielded $\mathrm{OR}=1.23[1.11-1.36] ; \mathrm{p}<0.0001$ and $\mathrm{OR}=0.93$ [0.89-0.96]; $\mathrm{p}=0.0005$, respectively. Interestingly, when CABG using bilateral internal mammary artery grafts was forced into the model (as a fourth variable in this study involving only $23 \mathrm{SWI}$ ), it evidenced an independent and significant association with SWI, without modifying 
Table I Pre- or Peri-operative Factors Associated with Sternal Wound Infection (SWI) in Univariate Analysis

\begin{tabular}{|c|c|c|c|c|c|}
\hline & $\begin{array}{l}\text { All Patients } \\
(n=182)\end{array}$ & $\begin{array}{l}\text { SWI Patients } \\
(n=23)\end{array}$ & $\begin{array}{l}\text { Patients without SWI } \\
(n=159)\end{array}$ & MD & $\mathbf{p}$ \\
\hline Male gender, n (\%) & I45 (79.6) & 17 (73.9) & $128(80.5)$ & 0 & $0.42^{\mathrm{a}}$ \\
\hline Median age [range] (years) & $68.5[45.0-87.0]$ & $68.0[47.0-82.0]$ & $69.0[45.0-87.0]$ & 0 & 0.72 \\
\hline Diabetes mellitus,n (\%) & $64(35.1)$ & $14(60.8)$ & $50(31.4)$ & I & 0.003 \\
\hline Arterial hypertension, $\mathrm{n}(\%)$ & $133(73.0)$ & $19(82.6)$ & II 4 (7I.6) & I & 0.14 \\
\hline Hypercholesterolemia, n (\%) & $12 \mid(66.4)$ & $15(65.2)$ & $106(66.6)$ & I & 0.88 \\
\hline Active smoking, n (\%) & $4 \mathrm{I}(22.5)$ & $5(21.7)$ & $36(22.6)$ & I & $0.99^{b}$ \\
\hline Immunodepression, $\mathrm{n}(\%)$ & $68(37.3)$ & $14(60.8)$ & $54(33.9)$ & I & 0.07 \\
\hline Obesity, n (\%) & $5 I(28.0)$ & $12(52.1)$ & $39(24.5)$ & 3 & 0.003 \\
\hline Overweight, n (\%) & $79(43.4)$ & $8(34.7)$ & $71(44.6)$ & 3 & 0.43 \\
\hline Median BMI [range] $\left(\mathrm{kg} / \mathrm{m}^{2}\right)$ & $27.7[18.7-50.5]$ & $30.7[23.0-50.5]$ & $27.5[18.7-42.4]$ & 3 & 0.002 \\
\hline Concomitant valve surgery, $\mathrm{n}(\%)$ & $26(14.2)$ & $3(13.0)$ & $23(14.4)$ & 0 & $0.99^{\mathrm{b}}$ \\
\hline Median number of grafts [range] & $2.0[1.0-4.0]$ & $2.0[2.0-4.0]$ & $2.0[1.0-4.0]$ & 0 & 0.48 \\
\hline Bilateral IMA ${ }^{b}$ grafts, $n(\%)$ & $138(75.8)$ & $21(91.3)$ & $117(73.5)$ & 0 & 0.06 \\
\hline Sequential grafts, $n(\%)$ & $50(27.4)$ & $4(17.3)$ & $46(28.9)$ & 0 & 0.24 \\
\hline Preoperative anaemia, n (\%) & $51(28.0)$ & II (47.8) & $40(25.1)$ & 0 & 0.02 \\
\hline Median preHb ${ }^{\mathrm{c}}$ [range] $(\mathrm{g} / \mathrm{L})$ & $135.0[95.0-\mid 83.0]$ & $129.0[95.0-154.0]$ & $137.0[105.0-183.0]$ & 0 & 0.004 \\
\hline Median postH $b^{d}$ [range] $(g / L)$ & II5.0 [88.0-149.0] & $115.0[91.0-139.0]$ & $115.0[88.0-149.0]$ & 0 & 0.42 \\
\hline Median $\Delta \mathrm{Hb}^{\mathrm{e}}[$ range] $(\mathrm{g} / \mathrm{L})$ & $-20.0[-64.0-+22.0]$ & $-10.0[-50.0-+9.0]$ & $-22.0[-64.0-+22.0]$ & 0 & 0.069 \\
\hline Patients transfused with RBC, $n(\%)$ & $131(71.9)$ & $21(94.3)$ & $110(69.1)$ & 0 & 0.02 \\
\hline $\begin{array}{l}\text { Median number of } \mathrm{RBC}^{f} \text { units transfused [range] } \\
\text { (units) }\end{array}$ & $2.0[0.0-29.0]$ & $3.0[0.0-29.0]$ & $2.0[0.0-13.0]$ & 0 & 0.001 \\
\hline Median Charlson Index [range] & $5.0[0.0-11.0]$ & $5.0[2.0-10.0]$ & $5.0[0.0-11.0]$ & 2 & 0.19 \\
\hline Median SAPSII ${ }^{g}$ score[range] & $25.0[12.0-48.0]$ & $24.0[20.0-39.0]$ & $25.0[12.0-48.0]$ & 112 & 0.89 \\
\hline Median ASA score [range] & $3.0[2.0-4.0]$ & $3.0[2.0-3.0]$ & $3.0[2.0-4.0]$ & 50 & 0.59 \\
\hline Median NNIS score [range] & $1.0[0.0-2.0]$ & I.0 $[0.0-2.0]$ & $1.0[0.0-2.0]$ & 55 & 0.66 \\
\hline Extracorporeal circulation duration (min) & $104.0[30.0-267.0]$ & $92.5[56.0-156.0]$ & $104[30.0-267.0]$ & 3 & 0.47 \\
\hline Surgery duration $(\min )$ & $240.0[100.0-470.0]$ & $240.0[165.0-300.0]$ & $245.0[100.0-470.0]$ & 5 & 0.70 \\
\hline
\end{tabular}

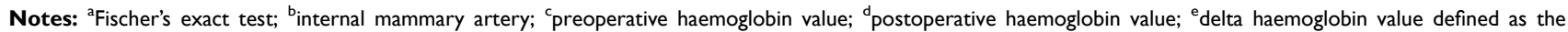
difference between postoperative and preoperative haemoglobin values; ${ }^{f}$ red blood cell units transfused during coronary artery bypass graft surgery or in intensive care unit; ${ }^{g}$ New Simplified Acute Physiology Score.

MD, missing data; BMI, body mass index; ASA, American Society of Anesthesiologists Score; NNIS, National Nosocomial Infection Surveillance Score.

the independent association with obesity, preoperative anaemia and number of RBC units transfused, but the Hosmer and Lemeshow goodness-of-fit fell to 0.16. The same preoperative factors (obesity, preoperative anaemia and number of RBC units transfused) were independently associated with SWI among the 138 patients undergoing
CABG using bilateral internal mammary artery grafts (Table 2).

Diabetes mellitus was statistically associated with obesity (49.0\% versus $29.6 \%$ among patients without obesity; $\mathrm{p}=0.01)$ but preoperative anaemia was not $(21.5 \%$ versus $31.2 \%$ among patients without obesity; $\mathrm{p}=0.19)$. The

Table 2 Pre- or Peri-operative Factors Independently Associated with Sternal Wound Infection in Multivariate Analysis Using a Stepwise Logistic Regression Model

\begin{tabular}{|l|l|l|l|l|l|l|}
\hline \multirow{2}{*}{} & \multicolumn{2}{|l|}{ All Patients $\mathbf{( n = 1 8 2 )}$} & \multicolumn{2}{l|}{ Bilateral IMA Patients (n=138) } \\
\cline { 2 - 7 } & $\mathbf{O R}^{\mathbf{b}}$ & $\mathbf{9 5 \%} \mathbf{C l}^{\mathbf{c}}$ & $\mathbf{P}$ & $\mathbf{O R}$ & $\mathbf{9 5 \%} \mathbf{C l}$ & $\mathbf{P}$ \\
\hline Obesity & 14.61 & {$[2.64-80.75]$} & 0.002 & 4.04 & {$[1.26-12.93]$} & 0.01 \\
Preoperative anaemia & 4.64 & {$[1.61-13.34]$} & 0.004 & 5.45 & {$[1.76-16.80]$} & 0.003 \\
Number of RBC units transfused & 1.27 & {$[1.02-1.58]$} & 0.03 & 1.47 & {$[1.09-1.96]$} & 0.009 \\
\hline
\end{tabular}

Abbreviations: CAD, coronary artery disease; CABG, coronary artery bypass graft surgery; SWI, sternal wound infection; CDC, Centre for Disease Control; BMI, body mass index; ARF, acute renal failure; RBC, red blood cell; ICU, intensive care unit; IMA, internal mammary artery grafts; OR, odds ratio; Cl, confidence interval. 
median number of RBC units transfused among patients with preoperative anaemia was statistically greater than that for patients without $(3.0[0.0-8.0]$ versus $2.0[0.0$ 29.0], $\mathrm{p}=0.0001$ ).

\section{Discussion/Conclusion}

This study confirmed that obesity, preoperative anaemia and the number of RBC units transfused were the main factors independently associated with SWI as we defined it, using a broader case definition than that of the CDC (see above). Both obesity and preoperative anaemia have been previously associated with SWI (deep or superficial) in larger studies with sophisticated statistical analyses. ${ }^{3,7,19-25}$ There is no doubt that the evidence contributed by these previous studies is more robust than that provided by our study without matching methods. However, the evidencing of these factors in a retrospective study in a single centre such as ours constitutes a supplementary argument for their general veracity.

Obesity was associated with SWI in the present study, and the main confounding factor was diabetes mellitus, which has been associated with obesity both here and elsewhere. ${ }^{19-22}$ The presence of diabetes mellitus (which accounted for a majority of cases of immunodeficiency as we defined it) was no longer associated with SWI when obesity, preoperative anaemia and the number of RBC units transfused were entered into the logistic regression model. This could suggest that obesity should be given more attention than diabetes mellitus regarding SWI after CABG, but it could also be due to a lack of power and to the small percentage of unbalanced diabetes mellitus $(25.0 \%)$ in the present study. Indeed, some past studies (but not all) have suggested a deleterious impact of uncontrolled glycaemia on SWI. ${ }^{2-28}$ Other studies have reported that obesity and diabetes mellitus entail the same risk of developing SWI after $\mathrm{CABG}^{29}$ In this latter study, smoking appeared as a risk factor for SWI, but not in ours, where only $12.1 \%$ of the patients did not stop smoking before the surgical procedure. This suggests that the percentage of patients with unbalanced diabetes mellitus or who did not stop smoking before the surgical procedure could modify the estimation of the impact of diabetes mellitus and smoking on the development of SWI across studies. Because obesity cannot be corrected quickly before elective $\mathrm{CABG}$, we presume that the independent association between obesity and SWI that we and others worldwide have observed remains relevant after $\mathrm{CABG},{ }^{30,31}$ but not after valve surgery. ${ }^{32}$

In addition to SWI, preoperative anaemia has also previously been associated with death, stroke, atrial fibrillation or ARF after heart surgery. ${ }^{25,33-35}$ This clearly suggests that the prevention of preoperative anaemia could be a target of interest before elective $\mathrm{CABG}$ in order to reduce morbidity and SWI among patients with obesity (which was not found to be linked to preoperative anaemia here or elsewhere). ${ }^{33}$ Preoperative anaemia seems all the more suitable as a target of interest because it remained independently associated with SWI even when the variable transfusion was entered into the logistic regression model. This suggests that transfusion (performed here exclusively during $\mathrm{CABG}$ or in the intensive care unit) cannot correct the deleterious impact of preoperative anaemia on the development of SWI. Conversely, some studies evidenced that RBC transfusion was associated with the development of SWI, but preoperative anaemia was not. ${ }^{36,37}$ An "immuno-modulating effect" of transfusion has been discussed, but the authors recognized that the timing and the reasons for RBC transfusion were not available in their retrospective study. ${ }^{37}$ Thus, they could not rule out the existence of further surgical complications requiring transfusion of a large number of RBC units, which could in itself explain the poorer prognosis that they observed. ${ }^{37}$ The deleterious impact of the transfusion of a large number of RBC units $(\geq 4)$ on the development of SWI has previously been reported, with significant interaction with preoperative anaemia. ${ }^{36}$ In our study, there was also an association between preoperative anaemia and the number of RBC units transfused, but the number of RBC units transfused was still independently associated with SWI, once obesity and preoperative anaemia had been entered into the logistic regression model (Table 2). Taken together, this suggests that acute bleeding during $\mathrm{CABG}$ requiring transfusion of a large number of $\mathrm{RBC}$ units, especially in case of preoperative anaemia, could be the physiopathological explanation leading to chest wall ischemia then SWI.

Indeed, the independent association of the number of $\mathrm{RBC}$ units transfused and the existence of preoperative anaemia and obesity with SWI in our study (especially in the case of $\mathrm{CABG}$ using bilateral internal mammary artery grafts) points to the mechanism of thoracic wall ischemia in SWI after CABG, leaving insufficient perfusion of the heavier thoracic wall (with higher basal metabolic rate) among patients with obesity. Such a mechanism is 
supported by the evidence of decreased blood supply to the chest wall after CABG using left internal mammary artery, and by the existence of chest wall necrosis after left or bilateral internal mammary graft harvesting for CABG. ${ }^{38-40}$ This chest wall ischemia leading to delayed wound healing is thought to favour the development of SWI that does not meet the CDC criteria. $^{7}$

Besides its retrospective and monocentric nature, the main limitation of the study is its conduct in the context of high prevalence of SWI before the implementation of systematic Staphylococcus aureus carriage decontamination in our centre. ${ }^{6}$ This could lead to a potential lack of reproducibility today, as well as the development of CABG using skeletonised internal mammary artery graft which has not been addressed in this study and which could reduce SWI incidence. ${ }^{5}$ However, more studies are needed to investigate the role of obesity and preoperative anaemia in the development of SWI, because these two preoperative factors seem to be better predictors of SWI than all the routinely performed scores (Charlson, SAPS, ASA and NNIS), and because SWI leads to prolonged hospitalisation, nephrotoxic antibiotherapy and ARF, but not mortality, here or elsewhere. ${ }^{1,19}$ Because SWI is costly, and because a lot of progress has been made in surgery, ${ }^{4,5}$ the implication of obesity medicine, vascular medicine and infectious disease specialists could help to resolve this emerging issue. ${ }^{1,41}$ Losing weight and reducing chest wall weight before elective CABG seems difficult, but strategies seeking to raise tissue oxygenation and preoperative haemoglobin such as preoperative RBC units transfusion and erythropoietin use need to be evaluated in terms of SWI reduction. ${ }^{42}$ Another strategy that has not been investigated here would be to optimize prophylactic antibiotic therapy for patients with obesity requiring CABG (eg we are not sure that injection of $1 \mathrm{~g}$ vancomycin provides a sufficient concentration immediately at the operating site among patients with obesity).

\section{Acknowledgment}

We are indebted to Dr Chadi Aludaat, Dr Paul Marticho and Dr Maxime Hentzien for their help in preparing this manuscript.

\section{Funding}

There is no funding to report.

\section{Disclosure}

The authors report no conflicts of interest for this work.

\section{References}

1. Carbone S, Canada JM, Billingsley HE, Siddiqui MS, Elagizi A, Lavie CJ. Obesity paradox in cardiovascular disease: where do we stand? Vasc Health Risk Manag. 2019;15:89-100. doi:10.2147/ VHRM.S168946

2. Mohr FW, Morice MC, Kappetein AP, et al. Coronary artery bypass graft surgery versus percutaneous coronary intervention in patients with three-vessel disease and left main coronary disease: 5-year follow-up of the randomised, clinical SYNTAX trial. Lancet. 2013;381(9867):629-638. doi:10.1016/S0140-6736(13)60141-5

3. Koshal A, Hendry P, Raman SV, Keon WJ. Should obese patients not undergo coronary artery surgery? Can J Surg. 1985;28(4):331-334.

4. Goldman S, Zadina K, Moritz T, et al. Long-term patency of saphenous vein and left internal mammary artery grafts after coronary artery bypass surgery: results from a Department of Veterans Affairs Cooperative Study. J Am Coll Cardiol. 2004;44(11):21492156. doi:10.1016/j.jacc.2004.08.064

5. Sá MP, Cavalcanti PE, de Andra de Costa Santos HJ, et al. Skeletonized versus pedicled bilateral internal mammary artery grafting: outcomes and concerns analyzed through a meta-analytical approach. Int J Surg. 2015;16(Pt B):146-152. doi:10.1016/j.ijsu.20 14.10.019

6. Bode LG, Kluytmans JA, Wertheim HF, et al. Preventing surgical-site infections in nasal carriers of Staphylococcus aureus. $N$ Engl J Med. 2010;362(1):9-17. doi:10.1056/NEJMoa0808939

7. Lemaignen A, Birgand G, Ghodhbane W, et al. Sternal wound infection after cardiac surgery: incidence and risk factors according to clinical presentation. Clin Microbiol Infect. 2015;21(7):674.e11-8. doi:10.1016/j.cmi.2015.03.025

8. Sajja LR. Strategies to reduce deep sternal wound infection after bilateral internal mammary artery grafting. Int $J$ Surg. 2015;16(Pt B):171-178. doi:10.1016/j.jjsu.2014.11.017

9. Ruka E, Dagenais F, Mohammadi S, Chauvette V, Poirier P, Voisine P. Bilateral mammary artery grafting increases postoperative mediastinitis without survival benefit in obese patients. Eur J Cardiothorac Surg. 2016;50(6):1188-1195. doi:10.1093/ejcts/ezw164

10. Pevni D, Medalion B, Mohr R, et al. Should bilateral internal thoracic artery grafting be used in patients with diabetes mellitus? Ann Thorac Surg. 2017;103(2):551-558. doi:10.1016/j.athoracsur.2016.06.044

11. Taggart DP, Benedetto U, Gerry S, et al. Bilateral versus single internal-thoracic-artery grafts at 10 years. $N$ Engl $J$ Med. 2019;380 (5):437-446. doi:10.1056/NEJMoa1808783

12. Dai C, Lu Z, Zhu H, Xue S, Lian F. Bilateral internal mammary artery grafting and risk of sternal wound infection: evidence from observational studies. Ann Thorac Surg. 2013;95(6):1938-1945. doi:10.1016/j.athoracsur.2012.12.038

13. Oswald I, Boening A, Pons-Kuehnemann J, Grieshaber P. Wound infection after $\mathrm{CABG}$ using internal mammary artery grafts: a metaanalysis. Thorac Cardiovasc Surg. 2020.

14. Bellomo R, Ronco C, Kellum JA, et al. Acute renal failure - definition, outcome measures, animal models, fluid therapy and information technology needs: the Second International Consensus Conference of the Acute Dialysis Quality Initiative (ADQI) Group. Crit Care. 2004;8(4):R204-R212. doi:10.1186/cc2872

15. Mayhew D, Mendonca V, Murthy BVS. A review of ASA physical status - historical perspectives and modern developments. Anaesthesia. 2019;74(3):373-379. doi:10.1111/anae.14569

16. Culver DH, Horan TC, Gaynes RP, et al. Surgical wound infection rates by wound class, operative procedure, and patient risk index. $\mathrm{Am}$ J Med. 1991;91(3B):152S-157S. doi:10.1016/0002-9343(91)90361-Z

17. Le Gall JR, Lemeshow S, Saulnier F. A new simplified acute physiology score (SAPS II) based on a European/North American multicenter study. JAMA. 1993;270(24):2957-2963. doi:10.1001/jama.19 93.03510240069035 
18. Charlson ME, Pompei P, Ales KL, MacKenzie CR. A new method of classifying prognostic comorbidity in longitudinal studies: development and validation. J Chronic Dis. 1987;40(5):373-383. doi:10.10 16/0021-9681(87)90171-8

19. Terada T, Johnson JA, Norris C, et al. Severe obesity is associated with increased risk of early complications and extended length of stay following coronary artery bypass grafting surgery. J Am Heart Assoc. 2016;5(6):pii: e003282. doi:10.1161/JAHA.116.003282

20. Vargo PR, Steffen RJ, Bakaeen FG, Navale S, Soltesz EG. The impact of obesity on cardiac surgery outcomes. J Card Surg. 2018;33(10):588-594. doi:10.1111/jocs.13793

21. Ghanta RK, LaPar DJ, Zhang Q, et al. Obesity increases risk-adjusted morbidity, mortality, and cost following cardiac surgery. J Am Heart Assoc. 2017;6(3):e003831. doi:10.1161/JAHA.116.003831

22. Chan PG, Sultan I, Gleason TG, et al. Contemporary outcomes of coronary artery bypass grafting in obese patients. J Card Surg. 2020;35(3):549-556. doi:10.1111/jocs.14415

23. Williams ML, He X, Rankin JS, Slaughter MS, Gammie JS. Preoperative hematocrit is a powerful predictor of adverse outcomes in coronary artery bypass graft surgery: a report from the society of thoracic surgeons adult cardiac surgery database. Ann Thorac Surg. 2013;96(5):1628-1634. doi:10.1016/j.athoracsur.2013.06.030

24. Vranken NP, Weerwind PW, Barenbrug PJ, Teerenstra S, Ganushchak YM, Maessen JG. The role of patient's profile and allogeneic blood transfusion in development of post-cardiac surgery infections: a retrospective study. Interact Cardiovasc Thorac Surg. 2014;19(2):232238. doi:10.1093/icvts/ivu096

25. Fowler AJ, Ahmad T, Phull MK, Allard S, Gillies MA, Pearse RM. Meta-analysis of the association between preoperative anaemia and mortality after surgery. Br J Surg. 2015;102(11):1314-1324. doi:10. 1002/bjs.9861

26. Narayan P, Kshirsagar SN, Mandal CK, et al. Preoperative glycosylated hemoglobin: a risk factor for patients undergoing coronary artery bypass. Ann Thorac Surg. 2017;104(2):606-612. doi:10.1016/ j.athoracsur.2016.12.020

27. Khan MR, Khan H, Wahab A, et al. Effect of glycemic control on mortality and infections in patients undergoing coronary artery bypass grafting: a Genesee County experience. J Community Hosp Intern Med Perspect. 2019;9(2):74-79. doi:10.1080/20009666.20 19.1581044

28. Biancari F, Giordano S. Glycated hemoglobin and the risk of sternal wound infection after adult cardiac surgery: a systematic review and meta-analysis. Semin Thorac Cardiovasc Surg. 2019;31(3):465-467. doi:10.1053/j.semtcvs.2019.02.029

29. Sá MP, Ferraz PE, Soares AF, et al. Development and validation of a stratification tool for predicting risk of deep sternal wound infection after coronary artery bypass grafting at a Brazilian Hospital. Braz J Cardiovasc Surg. 2017;32(1):1-7.
30. Biancari F, Gatti G, Rosato S, et al. Preoperative risk stratification of deep sternal wound infection after coronary surgery. Infect Control Hosp Epidemiol. 2020;41(4):444-451. doi:10.1017/ice.2019.375

31. Ali U, Bibo L, Pierre M, et al. Deep sternal wound infections after cardiac surgery: a new Australian tertiary centre experience. Heart Lung Circ. 2020;29(10):1571-1578. doi:10.1016/j.hlc.2020.02.003

32. Bruno VD, Chivasso P, Rapetto F, et al. Impact of body mass index on short- and long-term outcomes after isolated first-time surgical aortic valve replacement for aortic stenosis. J Cardiothorac Vasc Anesth. 2019;33(11):2995-3000. doi:10.1053/j.jvca.2019.02.015

33. Kulier A, Levin J, Moser R, et al. Impact of preoperative anemia on outcome in patients undergoing coronary artery bypass graft surgery. Circulation. 2007;116(5):471-479. doi:10.1161/CIRCULATIONAHA. 106.653501

34. Karkouti K, Wijeysundera DN, Beattie WS. Reducing Bleeding in Cardiac Surgery (RBC) Investigators. Risk associated with preoperative anemia in cardiac surgery: a multicenter cohort study. Circulation. 2008;117(4):478-484. doi:10.1161/CIRCULATIONAHA.107.718353

35. Miceli A, Romeo F, Glauber M, de Siena PM, Caputo M, Angelini GD. Preoperative anemia increases mortality and postoperative morbidity after cardiac surgery. J Cardiothorac Surg. 2014;9:137. doi:10.1186/1749-8090-9-137

36. Cutrell JB, Barros N, McBroom M, et al. Risk factors for deep sternal wound infection after cardiac surgery: influence of red blood cell transfusions and chronic infection. Am J Infect Control. 2016;44 (11):1302-1309. doi:10.1016/j.ajic.2016.03.027

37. Campos IC, Tanganelli V, Maues HP, et al. Blood transfusion and increased perioperative risk in coronary artery bypass grafts. Braz J Cardiovasc Surg. 2017;32(5):394-400.

38. Takami Y, Tajima K, Masumoto H. Near-infrared spectroscopy for noninvasive evaluation of chest wall ischemia immediately after left internal thoracic artery harvesting. Gen Thorac Cardiovasc Surg. 2008;56(6):281-287. doi:10.1007/s11748-008-0238-7

39. Johnson DY, Johnson FE, Barner HB. Abdominal wall necrosis after harvest of both internal thoracic and inferior epigastric arteries. Ann Thorac Surg. 2011;91(1):38-41. doi:10.1016/j.athoracsur.2010.08. 060

40. Wong MS, Kim J, Yeung C, Williams SH. Breast necrosis following left internal mammary artery harvest: a case series and a comprehensive review of the literature. Ann Plast Surg. 2008;61(4):368-374. doi:10.1097/SAP.0b013e3181640851

41. Phoon PHY, Hwang NC. Deep sternal wound infection: diagnosis, treatment and prevention. J Cardiothorac Vasc Anesth. 2020;34 (6):1602-1613. doi:10.1053/j.jvca.2019.09.019

42. Alghamdi AA, Albanna MJ, Guru V, Brister SJ. Does the use of erythropoietin reduce the risk of exposure to allogeneic blood transfusion in cardiac surgery? A systematic review and meta-analysis. $J$ Card Surg. 2006;21(3):320-326.
Vascular Health and Risk Management

\section{Publish your work in this journal}

Vascular Health and Risk Management is an international, peerreviewed journal of therapeutics and risk management, focusing on concise rapid reporting of clinical studies on the processes involved in the maintenance of vascular health; the monitoring, prevention and treatment of vascular disease and its sequelae; and the involvemen of metabolic disorders, particularly diabetes. This journal is indexed on PubMed Central and MedLine. The manuscript management system is completely online and includes a very quick and fair peerreview system, which is all easy to use. Visit http://www.dovepress. com/testimonials.php to read real quotes from published authors. 